\title{
ANÁLISE DO DESEMPENHO ACADÊMICO E INDICADORES DE GESTÃO DAS IFES
}

\section{ANALYSIS OF ACADEMIC PERFORMANCE MANAGEMENT INDICATOROS OF IFES}

\author{
Fátima de Souza Freire \\ Professora, Dra, Depto de Contabilidade/Universidade Federal do Ceará. \\ Av. da Universidade, 2431 - CEP 60020-180. Fone: 3366 7801/3366 7802 \\ e-mail: ffreire@ufc.br \\ Vicente Lima Crisóstomo \\ Professor, MSc, Depto de Contabilidade/Universidade Federal do Ceará. \\ Av. da Universidade, 2431 - CEP 60020-180. Fone: 3366 7801/3366 7802 \\ e-mail:vlc@ufc.br
}

\section{Juscelino Emanoel Gomes de Castro}

Bolsista, PIBIC-CNPq

Rua Rio Negro, 226; Sol-Mar; Ap-801; Caucaia - CEP 61635-025. Fone: 32851638

e-mail: juscelinoegcastro@yahoo.com.br

\section{RESUMO}

Este artigo tem como objetivo principal verificar se o desempenho administrativo das IFES, medido por um conjunto de indicadores de gestão, tem relação com o desempenho acadêmico. Nesta pesquisa inicial, realizou-se uma pesquisa numa amostra de 27 IFES no ano 2005. Os indicadores de gestão fixados são estabelecidos pelo TCU e o indicador de desempenho acadêmico dos alunos da graduação é medido pelo MEC, através do Enade. Os resultados obtidos mostraram um reflexo positivo de indicadores relacionados com o interesse discente em sua própria formação, medida pela taxa de sucesso e maior dedicação ao curso, e o IDD. $\mathrm{Na}$ mesma direção se encontrou um efeito favorável da relação entre número de alunos e 
funcionários. Entretanto, não se detectou um esperado efeito positivo do custo por aluno no desempenho deste como se esperava, considerando que se deseja que este indicador tenha influência positiva na qualidade do ensino.

Palavras-chave: Indicadores de desempenho, Enade, IFES.

\begin{abstract}
This paper has as main purpose checking if IFES' management performance, measured by a set of management indicators, is related to academic performance. In this initial research, a 27 IFES sample has been explored with year 2005 data. The management indicators are established by TCU and the academic performance indicator of students is measured by MEC, through Enade. The results found has shown a positive effect of indicators related to students' self interest with their own training, as measured by their success ratio and greater dedication to their under graduate course. In the same direction there has been found a favourable effect of the number of students-workers ratio. Nevertheless, no positive effect of the costs per student ratio has been detected as expected, considering the desirable positive influence of such indicator in the quality of education.
\end{abstract}

Key-words: Performance Indicators, Enade, IFES.

\title{
1. INTRODUÇÃO
}

Com as reformas administrativas de grande parte das funções do Estado nos anos 90, o governo brasileiro intensificou uma política de auto-avaliação e de regulação das ações econômicas e sociais. Nesse modelo, a educação superior foi tema de governo quanto à formação de recursos humanos centrada para um mercado cada vez mais competitivo. $\mathrm{O}$ Estado, como regulador de mercado, entendia que o sistema universitário deveria vincular-se a uma proposta de eficiência e produtividade.

Surgiram vários debates entre o governo e a sociedade para que fossem implantados projetos de modernização, orientados em programas neoliberais ensejados em reduções de gastos, aumento de pesquisas entre universidades e empresas, ampliação de pós-graduação, capacitação e valorização dos profissionais de educação. Por conseguinte, era necessário que todo o sistema educacional superior fosse avaliado, permitindo que as discussões de base filosófica deixassem de ser parâmetros quanto à oferta de serviços educacionais de qualidade. 
A avaliação institucional da educação superior é tema intrigante, já dizia Dias Sobrinho (2002, p.15) ao afirmar que "as relações de forças, que disputam a hegemonia e a direção de concepções, determinam as mudanças que essa instituição vai adquirindo ao longo dos tempos e dos diversos lugares". O ambiente da instituição é complexo, mediante a sua estrutura organizacional que é, muitas vezes, formal e burocrática, engessando a forma de gerenciamento; e mediante as relações entre profissionais, professores, pesquisadores e sociedade que são conduzidas pelas disputas ideológicas e políticas.

Desde 2002, o Tribunal de Contas da União (TCU), em decisão no 408/2002, determinou que as Instituições Federais de Ensino Superior (IFES) incorporassem nos seus relatórios de gestão nove indicadores de desempenho, com o intuito de construir uma série histórica da evolução de aspectos relevantes gerenciais, orientando a auditoria de natureza operacional quanto às boas práticas administrativas. Para o TCU tais indicadores são ferramentas auxiliadoras no acompanhamento do desempenho das entidades, servindo de instrumento de aprimoramento da gestão das IFES.

Por outro lado, o Ministério da Educação (MEC) criou o Sistema Nacional de Avaliação da Educação Superior (Sinaes) em 2004, pela Lei $\mathrm{n}^{\circ}$ 10.861, servindo de instrumento de avaliação da educação superior em três eixos: avaliação de instituições, avaliação de cursos e avaliação do desempenho dos alunos. Este último é realizado por meio do Exame Nacional de Desempenho dos Estudantes (Enade), com o objetivo de averiguar as habilidades acadêmicas e as competências profissionais desenvolvidas pelos estudantes ingressantes e concluintes das Instituições de Educação Superior (IES). Os estudantes são convocados pelo MEC para a realização de uma prova, dando subsídios para a criação de indicadores que trazem informações complementares sobre o desempenho das diferentes IES.

Este artigo focaliza as IFES com o intuito de averiguar empiricamente se há associação entre os indicadores de gestão e o indicador de desempenho dos estudantes. Objetiva-se saber se o bom desempenho das IFES por meio da avaliação do Enade é conseqüência de indicadores administrativos e operacionais. Quais indicadores de desempenho têm correlação com o resultado das provas dos estudantes da graduação? Enquanto as informações dos indicadores do TCU foram extraídas dos relatórios de gestão das IFES publicadas em seus sítios, o resultado do desempenho dos alunos no Enade, 
referente ao indicador de diferença entre os desempenhos observados dos estudantes ingressantes e concluintes (IDD), foi obtido no sítio do MEC. Para a realização do estudo, 27 instituições de um total de 54 IFES participaram da pesquisa, em 2005, tendo em vista que somente este número disponibilizava em seu sítio, em janeiro de 2007, informações de seus indicadores de gestão exigidos pelo TCU.

O trabalho se divide em 5 seções. A seção 2 apresenta, de forma descritiva, os indicadores de desempenho do MEC e indicadores do TCU. A seção 3 apresenta os dados e a metodologia utilizada na pesquisa. A seção 4 contém os resultados obtidos e algumas considerações sobre os mesmos. Por fim, a seção 5 apresenta as conclusões e perspectivas de continuidade do trabalho.

\section{INDICADORES DE DESEMPENHO ADMINISTRATIVO E ACADÊMICO DAS IFES}

\subsection{Indicadores de desempenho segundo o TCU}

Como os indicadores são instrumentos de apoio na avaliação de processos, antes de tratar deste assunto, é interessante que alguns conceitos sejam apresentados. Ristoff (2002, p.10) diz que avaliar é "antes de tudo um processo de autoconhecimento, de aprendizado institucional - um processo contínuo, permanente, global, democrático, legitimado politicamente, consolidado tecnicamente, e capaz de identificar os pontos fortes e fracos e as potencialidades da instituição no tempo e no espaço".

Cronbach citado por Ristoff (2003, p.21) diz que "avaliar significa simplesmente conduzir um estudo sistemático do que ocorre com um programa ou instituição e em conseqüência deles".

No caso das instituições de ensino, o processo de avaliação serve de instrumento de autoconhecimento, de tomada de decisão e de aperfeiçoamento permanente. Assim, o estudo dos indicadores de desempenho é de grande importância tanto no aspecto de controle, para que o gestor possa tomar as decisões, quanto no sentido de alocar melhor o recurso para a 
otimização das atividades. Wolynec (1992) defende a idéia de que, na avaliação das universidades públicas do país, é importante a definição de um conjunto de indicadores que permita a comparação entre instituições.

Em plenária do Tribunal de Contas da União, pela Decisão nº 408/2002, em 2002 foram criados indicadores de desempenho para IFES por um Grupo de Contato, formado por representantes do Tribunal de Contas da União, da Secretaria de Educação Superior SESu/MEC e da Secretaria Federal de Controle Interno - SFC. Este grupo teve como meta orientar as IFES na implantação padronizada do conjunto inicial de indicadores.

Silva, Morgan e Costa (2004) citam que os indicadores foram elaborados a partir da auditoria de natureza operacional realizada em seis IFES: Universidade Federal de Goiás UFGO, Fundação Universidade do Amazonas - FUA, Universidade Federal de Pernambuco UFPE, Universidade de Brasília - UNB, Universidade Federal do Rio de Janeiro - UFRJ e Universidade Federal do Rio Grande do Sul - UFRGS. Para o TCU, 9 (nove) indicadores, aqui denominados de índices, retratam o desempenho das IFES, são eles:

\section{Índice 1 - Custo Corrente / Aluno Equivalente \\ O índice 1 indica o custo por aluno na IFES.}

a) com hospital universitário (HU). Representa a relação do custo corrente aluno equivalente que é calculado com base: (i) nas despesas correntes de todas as unidades gestoras menos as despesas com sentenças judiciais, aposentadorias, reformas e pensões, pessoal afastado ou cedido e, também, $65 \%$ das despesas correntes dos hospitais universitários e maternidade; (ii) no aluno equivalente que é o número de alunos equivalentes da graduação, número de alunos tempo integral de pós-graduação e de residência médica.

b) sem hospital universitário. Representa a relação entre o custo corrente aluno equivalente que é calculado com base: (i) nas despesas correntes de todas as unidades gestoras menos as despesas com sentenças judiciais, aposentadorias, reformas e pensões, pessoal afastado ou cedido e, também, 100\% das despesas correntes dos hospitais universitários e maternidade; (ii) aluno equivalente - número de alunos equivalentes da graduação, número de alunos tempo integral de pós-graduação e de residência médica. 


\section{Índice 2 - Aluno Tempo Integral / Professor}

O índice 2 evidencia a relação entre o número de alunos em tempo integral e número de professores equivalentes. Aqui deve ser considerado o docente de tempo (40 horas/semana, com ou sem dedicação exclusiva-DE), convertendo-se proporcionalmente os que se enquadram em outros regimes de dedicação (20 horas/semana - peso 0,50; 40 horas/semana peso 1,00; dedicação exclusiva - peso 1,00). Deve-se excluir professores afastados e aqueles de ensino médio.

\section{Índice 3 - Aluno Tempo Integral / Funcionário}

$\mathrm{O}$ índice 3 mostra a relação entre força de trabalho administrativa e o número de alunos.

a) Com hospital universitário. Representa a relação entre o número de alunos tempo integral e número total de funcionários Equivalentes com HU. Deve ser considerado o servidor de tempo (40 horas/semana), convertendo-se proporcionalmente os que se enquadra em outros regimes de trabalho (20 horas/semana - peso 0,50; 30 horas/semana - peso 0,75; 40 horas/semana peso 1,00). Deve-se incluir professores de ensino médio e fundamental e também os servidores e prestadores de serviço não vinculados, direta ou indiretamente, às atividades de ensino e pesquisa. Excluir funcionários afastados.

b) Sem hospital universitário. Representa a relação entre o custo corrente aluno equivalente que é calculado com base: (i) nas despesas correntes de todas as unidades gestoras menos as despesas com sentenças judiciais, aposentadorias, reformas e pensões, pessoal afastado ou cedido e, também, $100 \%$ das despesas correntes dos hospitais universitários e maternidade; (ii) aluno equivalente - número de alunos equivalentes da graduação, número de alunos tempo integral de pós-graduação e de residência médica.

\section{Índice 4 - Funcionário / Professor}

O índice 4 mostra a relação entre força de trabalho docente e o número de alunos.

a) Com hospital universitário. Representa a relação entre o número de funcionários equivalentes com HU e número de professores equivalentes.

b) Sem hospital universitário. Representa a relação entre o número de funcionários equivalentes sem HU e número de professores equivalentes. 


\section{Índice 5 - Grau de Participação Estudantil}

O índice 5 indica o número de alunos da graduação com dedicação em tempo integral ao curso. Este índice leva em consideração número de diplomados, no ano letivo referente ao exercício, em cada curso; duração padrão do curso, de acordo com a tabela da SESu; número de alunos que ingressaram, no ano letivo relativo ao exercício, em cada curso segundo fator de retenção calculado de acordo com metodologia da SESu.

\section{Índice 6 - Grau de Envolvimento com a Pós-Graduação}

O índice 6 mostra a intensidade do envolvimento discente com a pós-graduação stricto sensu. O índice é obtido pela razão entre o total de alunos efetivamente matriculados em programas de mestrado e doutorado (pós-graduação stricto sensu), e o total de alunos efetivamente matriculados na IFES, incluindo-se aí todo o contingente de graduação, mestrado e de doutorado; e alunos de residência médica.

\section{Índice 7 - Conceito CAPES}

O índice 7 representa a relação entre a média aritmética das notas de avaliação realizada pela Coordenação de Aperfeiçoamento de Pessoal de Nível Superior (Capes) de todos os cursos de mestrado e doutorado (não considera os mestrados profissionalizantes) e número de programas de pós-graduação.

\section{Índice 8 - Índice de Qualificação do Corpo Docente (IQCD)}

O índice 8 é um indicador do grau de qualificação docente. Aqui são atribuídas as seguintes ponderações aos professores: docentes doutores (peso 5), docentes mestres (peso 3), docentes com especialização (peso 2) e docentes graduados (peso 1). Divide-se então o resultado obtido pelo número total de professores. O índice máximo alcançável é 5 (cinco).

\section{Índice 9 - Taxa de Sucesso na Graduação}

O índice 9 representa a relação entre o número de diplomados e número total de alunos ingressantes. Deve-se considerar o número de concluintes (que completaram os créditos, mesmo não tendo colado grau) dos cursos no ano letivo correspondente ao exercício, somando-se o número de concluintes nos dois semestres do ano.

\subsection{Indicador de diferença entre os desempenhos observado e esperado (IDD)}


O processo de implementação de um sistema de avaliação do ensino superior teve início com a Lei 9.131 de 1996 (BRASIL, 1995), chamado de Exame Nacional de Cursos (ENC), a ser aplicado a todos os estudantes concluintes de campos de conhecimento prédefinidos. Com a chegada do governo de Luis Inácio Lula da Silva, o sistema foi remodelado dando origem ao SINAES - Sistema Nacional de Avaliação da Educação Superior (GUTERRES, 2004).

No processo de avaliação da educação superior estão previstas as seguintes ações: I avaliação dos principais indicadores de desempenho global do sistema nacional de educação superior; II - avaliação institucional do desempenho individual das instituições de ensino superior, considerado; III - avaliação dos cursos superiores, mediante a análise dos resultados do Exame Nacional de Cursos e das condições de oferta de cursos superiores.

Toda esta operacionalização é realizada pela Comissão Nacional de Avaliação da Educação Superior - CONAES. Cabe a ela definir diretrizes, estabelecer procedimentos e mecanismos para o desenvolvimento das instituições, criando comissões próprias de avaliação em busca de detectar qual a contribuição de cada curso e de cada instituição na formação dos alunos.

O Enade, instituído pela Lei 10.861 de 2004, é o terceiro instrumento usado na avaliação do ensino superior que aplica um exame para uma amostra de estudantes - do primeiro e do último ano - de cursos selecionados anualmente pelo MEC. De acordo com o SINAES, em seu art. $5^{\circ}, \S 5^{\circ}$, o Enade é "componente curricular obrigatório dos cursos de graduação, sendo inscrita no histórico escolar do estudante somente a sua situação regular com relação a essa obrigação, atestada pela sua efetiva participação ou, quando for o caso, dispensa oficial pelo Ministério da Educação, na forma estabelecida em regulamento". O Enade Conceito é calculado pela "média ponderada da nota padronizada dos concluintes no componente específico, da nota padronizada dos ingressantes no componente específico e da nota padronizada em formação geral (concluintes e ingressantes), possuindo estas, respectivamente, os seguintes pesos: $60 \%, 15 \%$ e 25\%. Assim, a parte referente ao componente específico contribui com $75 \%$ da nota final, enquanto a referente à formação geral contribui com $25 \%$." 
O Indicador de Diferença entre os Desempenhos Observado e Esperado (IDD) mostra informações comparativas dos desempenhos dos estudantes concluintes em relação aos resultados obtidos, em média, pelas demais instituições cujos perfis de estudantes ingressantes são semelhantes. Para o MEC as informações extraídas no IDD apresentam boas aproximações do que seria considerado efeito do curso, pois é observada a relação existente entre o perfil dos ingressantes e dos estudantes concluintes do mesmo curso. Cada curso terá uma nota em função do resultado da média ponderada das notas de formação geral - FG e de conteúdo específico - CE, com pesos de 0,25 e 0,75, respectivamente, indicando a quantidade de acertos em uma escala de 0 a 100. Após o cálculo, o IDD é padronizado, subtraindo-se a média dos cursos e dividindo pelo desvio padrão das médias dos cursos por área. Isso resulta em um índice cuja unidade de medida é o desvio padrão. Os resultados das avaliações são expressos por meio de conceitos, numa escala de cinco níveis, representando: 5 e 4 indicativos de pontos fortes; 3 , mínimo aceitável; 2 e 1, indicativos de pontos fracos. O IDD Conceito é "uma transformação do IDD Índice, de forma que ele seja apresentado em cinco categorias ( 1 a 5) sendo que 1 é o resultado mais baixo e 5 é o melhor resultado possível no IDD Conceito".

Rothen (2003) aponta algumas características do exame nacional de cursos (antigo provão), permitindo reflexões sobre o sistema de avaliação de IES, tais como:

- tem como propósito conduzir a homogeneização dos cursos de graduação por meio de diretrizes curriculares;

- possibilita a divulgação de um ranking das ies bem e mal avaliadas;

- induz a opinião pública a comparar a média dos cursos às notas necessárias para aprovação por um aluno em uma disciplina;

- não avalia o desempenho dos alunos com base num currículo mínimo, pois as diretrizes curriculares definem aspectos gerais da organização dos cursos de graduação e as ies elaboram grades curriculares diferentes;

- tais testes não possibilitam que nenhum curso mal avaliado seja fechado;

- não há equivalência entre as notas obtidas por instituições no exame e a nota isolada por um aluno em disciplinas isoladas;

- a avaliação de cursos é um instrumento de marketing governamental. 
ISSN 1676 - 1901 / Edição especial/dezembro de 2007 Artigo selecionado dos anais XIV Congresso Brasileiro de Custos

\subsection{Hipóteses}

Até o ponto em que se tem conhecimento, ainda não há teorias conclusivas que fundamentem os fatores que efetivamente possam ser determinantes do desempenho discente medido pelo IDD. Entretanto, considerando a natureza de cada indicador de desempenho das instituições, pode-se considerar o possível efeito que esta possa ter no desempenho discente. A partir deste raciocínio, propõe-se um conjunto de hipóteses sobre os possíveis, ou esperados, efeitos que os indicadores possam ter sobre o desempenho acadêmico dos seus egressos, como se apresenta a seguir.

$\mathrm{O}$ índice 1 corresponde à relação entre custo corrente e aluno equivalente e indica o custo por aluno da instituição. Em princípio, um maior custo por aluno deve traduzir-se em melhores instalações e serviços da instituição disponibilizados ao alunado ao longo de sua formação, o que deve resultar em mais qualidade neste processo. Alunos com melhor formação tendem a obter melhores desempenhos em sistemas de avaliação como o Enade. Esta argumentação nos permite prever uma relação direta entre o IDD e o indicador de custo corrente aluno equivalente.

No tocante à relação número de alunos por professores (índice 2), entende-se que quanto maior o número de professores relativamente ao de alunos, melhor será a atenção a estes últimos. Isto significa que quanto menor for o resultado, melhor será este índice. Nesta direção, espera-se que haja uma relação inversa entre este índice e a formação do alunado. Um resultado primeiro desta formação pode ser o desempenho do aluno no Enade. Neste sentido, propõe como hipótese que há uma relação inversa entre o índice 2 e o IDD.

De modo análogo aos argumentos, relativamente ao índice 3, entende-se que um maior número de funcionários à disposição dos alunos se traduzirá em melhor atenção e melhor formação para os mesmos. Isto leva a propor uma hipótese de uma relação inversa entre o índice 3 e o IDD.

A relação entre número de funcionários e de professores (índice 4) indica uma relação entre o tamanho do corpo de apoio indireto ao aluno e ao professor e o tamanho do corpo de apoio e atendimento direto ao aluno. Os dois grupos têm importância fundamental para a boa formação do aluno. Entretanto, o apoio direto dado pelo professor se reveste de maior relevo. 
Isto permite considerar que é melhor um maior número de professores com relação ao de funcionários para a formação do aluno. Deste modo, tem-se como hipótese que há uma relação inversa entre este índice e o desempenho do aluno.

Com relação à participação estudantil aproximada pela relação entre número de alunos de graduação de tempo integral e o número total de alunos ativos na graduação (índice 5), sugere-se que quanto mais alunos em tempo integral, melhor será para sua formação e possivelmente melhor será o seu desempenho futuro. Deste modo, tem-se a hipótese de que há uma relação positiva entre o IDD e o índice 5.

O maior envolvimento discente com a pós-graduação (índice 6) pode gerar um efeito positivo no desempenho do aluno, uma vez que uma pós-graduação forte implica em mais laboratórios, bibliotecas, grupos e projetos de pesquisa ativos e bolsas, além do natural mais intenso intercâmbio de conhecimento que acaba também por envolver o ensino na graduação. Este raciocínio permite propor a hipótese de que há uma relação positiva entre o IDD e o índice 6.

Um melhor conceito para a pós-graduação (índice 7) pode ter relação positiva com o desempenho dos graduandos, considerando que uma melhor pós-graduação deve indicar que a graduação vai bem. É de se esperar que departamentos capazes de manter pós-graduação de bom nível, também são capazes de ter bons cursos de graduação. Esta lógica permite gerar uma hipótese de que há uma relação positiva entre o índice 7 e o IDD.

Uma melhor qualificação docente (índice 8) é um indicativo de professores mais preparados e envolvidos com as atividades de pesquisa, extensão e, principalmente, ensino. Professores mais qualificados envolvidos no ensino significa ter influência na qualidade da formação do aluno. A partir deste raciocínio, propõe-se a hipótese de que há uma relação positiva entre o IDD e o índice 8.

A taxa de sucesso na graduação (índice 9) é um sinal de realização do curso em tempo regular, o que indica mais interesse e dedicação do aluno para sua formação. Espera-se que este índice apresente uma relação positiva com o IDD. 


\section{DADOS E METODOLOGIA}

\subsection{Dados}

Os dados indicadores de desempenho de cada IFES foram coletados a partir dos seus relatórios gerenciais e de relatórios do MEC sobre o ensino superior no Brasil. Das 54 IFES existentes no país, 50\% delas, ou seja, 27 foram selecionadas para o estudo inicial por questão de limitação na disponibilidade de informações. Estas IFES publicaram relatórios gerenciais em 2005, demonstrando conhecimento no preenchimento do modelo do TCU e apresentando informações adicionais na Internet. Além disto, também se pode destacar que as IFES da amostra estão distribuídas geograficamente no território nacional, o que evita alguma eventual tendência que possa existir por este fator. Conforme apresentadas na tabela 1, das IFES estudadas, aproximadamente $37 \%$ estão localizadas na região Sudeste, em torno de $22 \%$ na região Nordeste, $18,52 \%$ na região Sul e na região Norte e 3,7\% na região Centro-Oeste.

Pela complexidade existente nas IFES, uma vez que nem todas possuem os mesmos cursos e nem participam do mesmo teste, foi calculado para cada IFES um IDD médio dos cursos avaliados pelo MEC. A instituição com maior número de cursos avaliados foi a UFRJ, seguida da UFMG e da FFFCMPA. Enquanto isto, a UNIFAL-MG, CEFET-PR e UFTO tiveram o menor número de cursos avaliados. A tabela 1 exibe um quadro detalhado do número de cursos avaliados por IFES, bem como os valores médios dos resultados no Enade e no IDD, de desvio padrão relativos aos indicadores do Enade e IDD de 2005. Enquanto o valor máximo dos indicadores ficou em 4,0, o valor mínimo do Enade Conceito ficou em 2,5 e o IDD Conceito em 1,7. Logo, a média do Enade foi superior ao IDD. No entanto, o desvio padrão do IDD médio apresentou resultado acima da média, ficando em 0,43.

O período de abrangência da pesquisa foi o ano de 2005, porque a metodologia criada pelo TCU para o cálculo dos indicadores sofreu ajuste nesta época, impossibilitando que dados dos indicadores de anos anteriores fossem comparados. Para esta pesquisa inicial, realizou-se uma pesquisa exploratória do conjunto de IFES e de seus indicadores administrativos e de desempenho de seus alunos no Enade. Neste sentido, realizou-se uma pesquisa descritiva dos diversos índices com o objetivo de ter uma boa visão do conjunto de 
IFES pesquisada. Esta primeira fase consiste num levantamento de dados descritivos (tabela 2) e, através da divisão da amostra por tamanho das IFES, buscou-se alguma eventual diferença de médias de índices entre universidades maiores e menores. A segunda etapa da pesquisa consistiu em buscar relações entre os índices administrativos e o desempenho dos alunos medidos pelo IDD, através de análise em corte transversal.

As variáveis utilizadas são os índices administrativos (seção 2.1) e o IDD, além do indicador aluno equivalente total (NFTE), utilizado pelo MEC, que se fez uso como uma aproximação do número de alunos da IFES, considerado como um bom indicativo para o tamanho da IFES (TAM). Para balancear algumas flutuações neste número, calculou-se a média do NFTE dos anos de 2002 a 2004 para aproximar o tamanho pela média. 
Tabela 1 - Dados descritivos do número de cursos avaliados e dos resultados do Enade por IFES

\begin{tabular}{|c|c|c|c|c|c|c|}
\hline \multirow[b]{2}{*}{ Região } & \multirow[b]{2}{*}{$\%$} & \multirow[b]{2}{*}{27 IFES } & \multicolumn{2}{|c|}{ Enade Conceito } & \multicolumn{2}{|c|}{ IDD Conceito } \\
\hline & & & $\begin{array}{l}\text { Número de } \\
\text { cursos } \\
\text { avaliados } \\
\text { com Enade } \\
\text { Conceito }\end{array}$ & $\begin{array}{l}\text { Resultado } \\
\text { médio do } \\
\text { Enade } \\
\text { Conceito }\end{array}$ & $\begin{array}{l}\text { Número de } \\
\text { cursos } \\
\text { avaliados } \\
\text { com IDD } \\
\text { Conceito } \\
\end{array}$ & $\begin{array}{l}\text { Resultado } \\
\text { médio do } \\
\text { IDD } \\
\text { Conceito }\end{array}$ \\
\hline \multirow{5}{*}{ Norte } & \multirow{5}{*}{$18,52 \%$} & UFAC & 9 & 3,2 & 8 & 3,1 \\
\hline & & UFRA & 32 & 2,6 & 30 & 2,5 \\
\hline & & UNIFAP & 10 & 2,8 & 8 & 2,5 \\
\hline & & UNIR & 9 & 2,9 & 7 & 3,0 \\
\hline & & UFTO & 5 & 3,2 & 4 & 2,8 \\
\hline \multirow{6}{*}{ Nordeste } & \multirow{6}{*}{$22,22 \%$} & UFAL & 24 & 2,5 & 18 & 2,8 \\
\hline & & UFERSA(ESAM) & 10 & 3,5 & 5 & 3,0 \\
\hline & & UFBA & 16 & 3,6 & 14 & 3,1 \\
\hline & & UFC & 18 & 3,1 & 18 & 3,1 \\
\hline & & UFPB & 20 & 3,5 & 16 & 3,1 \\
\hline & & UFPE & 16 & 3,5 & 15 & 3,1 \\
\hline $\begin{array}{c}\text { Centro- } \\
\text { Oeste }\end{array}$ & $3,70 \%$ & UFG & 15 & 3,7 & 13 & 2,7 \\
\hline \multirow{10}{*}{ Sudeste } & \multirow{10}{*}{$37,04 \%$} & CEFET-RJ & 4 & 3,5 & 4 & 2,8 \\
\hline & & UFES & 24 & 3,3 & 24 & 3,1 \\
\hline & & UFF & 33 & 2,9 & 22 & 3,3 \\
\hline & & UNIFAL-MG & 3 & 4,0 & 3 & 4,0 \\
\hline & & UFTM & 16 & 2,9 & 16 & 3,2 \\
\hline & & UFU & 31 & 3,5 & 28 & 3,1 \\
\hline & & UFLA & 8 & 3,0 & 7 & 2,3 \\
\hline & & UNIFEI & 15 & 3,8 & 11 & 3,4 \\
\hline & & UFRJ & 160 & 3,3 & 135 & 2,8 \\
\hline & & UFMG & 63 & 3,8 & 61 & 3,2 \\
\hline \multirow{5}{*}{ Sul } & \multirow{5}{*}{$18,52 \%$} & UFSC & 25 & 3,4 & 19 & 3,2 \\
\hline & & CEFET-PR & 3 & 3,7 & 3 & 1,7 \\
\hline & & FFFCMPA & 48 & 3,9 & 43 & 3,4 \\
\hline & & UFRG & 12 & 3,7 & 12 & 3,6 \\
\hline & & UFPEL & 18 & 3,0 & 15 & 2,9 \\
\hline \multicolumn{3}{|c|}{ Média } & & 3,33 & & 2,99 \\
\hline \multicolumn{3}{|c|}{ Desvio padrão } & & 0,40 & & 0,43 \\
\hline \multirow{2}{*}{\multicolumn{3}{|c|}{$\begin{array}{l}\text { Valor máximo } \\
\text { Valor mínimo }\end{array}$}} & & 4,0 & & 4,0 \\
\hline & & & & 2,5 & & 1,7 \\
\hline
\end{tabular}

Fonte: Adaptações de dados do MEC

A tabela 2 nos apresenta estatísticas descritivas da amostra completa. Talvez mereça a pena comentar o custo anual médio por aluno de aproximadamente $\mathrm{R} \$ 7.500,00$ reais (aproximadamente US\$ 3.900,00) e uma relação de 13,05 alunos por professor e 9,51 alunos por funcionário administrativo. Uma comparação relativa destes índices com outros conjuntos 
de instituições de ensino superior faz parte da continuidade deste trabalho. Neste ponto da pesquisa procurou-se aprofundar o conhecimento sobre o conjunto de IFES. Dividindo a amostra por região (tabela 3), verifica-se que há uma certa homogeneidade nos valores médios, em geral, tanto dos índices administrativos como do IDD. Uma verificação de diferenças estatisticamente significativas entre regiões não foi possível pelo reduzido número de IFES por região. Merece menção, talvez, a já esperada diferença de tamanho das instituições entre regiões, estando as menores no Norte do país. No entanto, a ausência de algumas instituições pode prejudicar este resultado. As universidades do Sul e Sudeste apresentaram alguma superioridade no índice 8 (capacitação docente) e no índice 7 (conceito de pós-graduação) como já se esperava, uma vez que estas universidades já têm mais tradição na pós-graduação, além de muitas serem mais antigas.

Tabela 2 - Estatísticas descritivas da amostra

\begin{tabular}{rrrrrrrrrrrr}
\hline & TAM & IDD & I1 & \multicolumn{1}{c}{ I2 } & I3 & I4 & I5 & I6 & I7 & I8 & I9 \\
\hline Média & $16.736,28$ & 2,98 & $7.496,19$ & 13,05 & 9,51 & 1,61 & 0,84 & 0,105 & 3,80 & 3,57 & 0,64 \\
DPadrão & $14.394,95$ & 0,44 & $2.773,90$ & 3,65 & 3,67 & 0,81 & 0,13 & 0,074 & 0,53 & 0,52 & 0,21 \\
Mediana & $14.965,33$ & 3,06 & $7.017,89$ & 12,73 & 9,16 & 1,50 & 0,83 & 0,100 & 3,77 & 3,61 & 0,61 \\
Mínimo & $1.923,00$ & 1,67 & $4.010,22$ & 8,23 & 3,78 & 0,41 & 0,60 & 0,006 & 3,00 & 2,40 & 0,12 \\
Máximo & $48.924,00$ & 4,00 & $18.263,19$ & 27,17 & 20,11 & 3,93 & 1,12 & 0,290 & 4,88 & 4,67 & 1,02 \\
\hline \multicolumn{1}{c}{ Fonte: Elaboração própria }
\end{tabular}

A partir destas informações, um conjunto de fatores relatados a continuação nos permite considerar que temos uma boa amostra para a realização do estudo e atingir os objetivos propostos. A amostra está composta por $50 \%$ do conjunto de IFES, com observações distribuídas por todas as regiões do território nacional. Além disto, como se pode ver na tabela 2, as universidades pesquisadas estão bem distribuídas no que se refere ao tamanho, como se pode ver pelo alto desvio padrão do tamanho, o que permite afirmar que a amostra contém grandes, médias e pequenas IFES, não havendo, portanto, a influência deste fator nos resultados. Adicionalmente a este fato, utilizou-se o teste hadimvo do Stata 9.2 que confirmou a ausência de valores extremos na variável tamanho. Um teste adicional de detecção de valores extremos foi realizado para todas as variáveis utilizando a estratégia de Hall (1992) de considerar um valor extremo aquele que está fora do intervalo que tem como 
valor mínimo a mediana menos 5 vezes o interquartil e de máximo a mediana mais 5 vezes o interquartil.

Tabela 3 - Estatísticas descritivas da amostra por região

\begin{tabular}{|c|c|c|c|c|c|c|c|c|c|c|c|}
\hline Região/Estast. & TAM & IDD & I1 & $\mathrm{I} 2$ & $\mathrm{I} 3$ & I4 & I5 & I6 & I7 & I8 & I9 \\
\hline \multicolumn{12}{|l|}{$\begin{array}{l}\text { Norte } \\
18,52, \%)\end{array}$} \\
\hline Média & $4.967,13$ & 2,77 & $7.076,18$ & 12,9 & 9,41 & 1,74 & 0,75 & 0,04 & 3,25 & 3,05 & 0,57 \\
\hline Desv. Padr. & $2.181,00$ & 0,29 & $2.442,39$ & 3,09 & 4,30 & 1,25 & 0,12 & 0,04 & 0,20 & 0,53 & 0,15 \\
\hline Mediana & $5.457,33$ & 2,75 & $7.195,77$ & 12,54 & 9,77 & 1,28 & 0,70 & 0,02 & 3,25 & 3,04 & 0,54 \\
\hline Mínimo & $2.047,67$ & 2,47 & $4.387,54$ & 8,98 & 3,78 & 0,74 & 0,64 & 0,01 & 3 & 2,40 & 0,43 \\
\hline Máximo & $7.806,00$ & 3,13 & $10.671,11$ & 16,91 & 15,18 & 3,92 & 0,94 & 0,10 & 3,50 & 3,82 & 0,82 \\
\hline \multicolumn{12}{|l|}{$\begin{array}{r}\text { Nordeste }(\mathrm{N}=6 ; \\
22,22 \%)\end{array}$} \\
\hline Média & $20.758,67$ & 3,01 & $7.340,83$ & 13,31 & 8,49 & 1,80 & 0,84 & 0,09 & 3,84 & 3,47 & 0,60 \\
\hline Desv. Padr. & $10.354,50$ & 0,11 & $1.149,91$ & 1,22 & 3,39 & 0,69 & 0,11 & 0,04 & 0,30 & 0,48 & 0,09 \\
\hline Mediana & $24.893,67$ & 3,06 & $7.176,62$ & 13,51 & 8,35 & 1,52 & 0,83 & 0,10 & 3,92 & 3,42 & 0,60 \\
\hline Mínimo & $1.923,00$ & 2,78 & $5.859,10$ & 11,32 & 4,87 & 0,98 & 0,71 & 0,04 & 3,29 & 2,97 & 0,51 \\
\hline Máximo & $29.033,00$ & 3,07 & $8.941,12$ & 14,80 & 14,24 & 2,69 & 1,01 & 0,16 & 4,07 & 4,30 & 0,77 \\
\hline \multicolumn{12}{|l|}{$\begin{array}{l}\text { Centro-Oeste } \\
(\mathrm{N}=1 ; 3,70 \%)\end{array}$} \\
\hline Média & $24.974,00$ & 2,69 & $6.775,34$ & 14,44 & 14,75 & 0,97 & 0,97 & 0,10 & 3,50 & 3,90 & 0,67 \\
\hline \multicolumn{12}{|l|}{ Desv. Padr. } \\
\hline Mediana & $24.974,00$ & 2,69 & $6.775,34$ & 14,44 & 14,75 & 0,97 & 0,97 & 0,10 & 3,50 & 3,90 & 0,67 \\
\hline Mínimo & $24.974,00$ & 2,69 & $6.775,34$ & 14,44 & 14,75 & 0,97 & 0,97 & 0,10 & 3,50 & 3,90 & 0,67 \\
\hline Máximo & $24.974,00$ & 2,69 & $6.775,34$ & 14,44 & 14,75 & 0,97 & 0,97 & 0,10 & 3,50 & 3,90 & 0,67 \\
\hline \multicolumn{12}{|l|}{$\begin{array}{r}\text { Sudeste }(\mathrm{N}=10 \\
37,04 \%)\end{array}$} \\
\hline Média & $18.782,10$ & 3,11 & $8.352,33$ & 14,14 & 8,17 & 1,81 & 0,89 & 0,14 & 3,98 & 3,92 & 0,71 \\
\hline Desv. Padr. & $18.234,58$ & 0,44 & $3.857,59$ & 4,92 & 1,90 & 0,67 & 0,12 & 0,09 & 0,71 & 0,38 & 0,24 \\
\hline Mediana & $13.029,17$ & 3,16 & $8.039,62$ & 12,91 & 8,24 & 1,56 & 0,85 & 0,13 & 3,96 & 3,89 & 0,76 \\
\hline Mínimo & $2.820,67$ & 2,29 & $4.010,22$ & 9,83 & 3,84 & 1,02 & 0,76 & 0,006 & 3,00 & 3,43 & 0,12 \\
\hline Máximo & $48.924,00$ & 4,00 & $18.263,19$ & 27,17 & 11,03 & 3,36 & 1,12 & 0,29 & 4,88 & 4,67 & 0,94 \\
\hline \multicolumn{12}{|l|}{ Sul $(\mathrm{N}=5 ; 18,52 \%)$} \\
\hline Média & $17.939,40$ & 2,95 & $6.294,14$ & 10,44 & 13,22 & 0,90 & 0,84 & 0,11 & 3,90 & 3,46 & 0,60 \\
\hline Desvio Padrão & $15.275,68$ & 0,77 & $2.106,00$ & 2,96 & 4,72 & 0,43 & 0,15 & 0,077 & 0,31 & 0,45 & 0,30 \\
\hline Mediana & $14.965,33$ & 3,21 & $5.876,40$ & 9,75 & 11,64 & 0,90 & 0,87 & 0,09 & 3,75 & 3,49 & 0,58 \\
\hline Mínimo & $2.865,67$ & 1,67 & $4.381,77$ & 8,23 & 9,50 & 0,41 & 0,60 & 0,04 & 3,60 & 2,88 & 0,18 \\
\hline Máximo & 34970,00 & 3,58 & $9.042,00$ & 15,43 & 20,11 & 1,38 & 1,02 & 0,23 & 4,24 & 4,09 & 1,02 \\
\hline
\end{tabular}

Os demais dados referentes aos indicadores também se apresentam dentro de valores esperados, não havendo variáveis com valores muitos extremos (outliers). Merece observar-se que o índice 5 (Grau de Participação Estudantil) apresenta uma notória baixa variabilidade indicando uma homogeneidade do conjunto em termos de número de alunos em tempo integral frente ao conjunto total de estudantes.

Antes de avançar na análise multidimensional, visando aprofundar o conhecimento deste conjunto de instituições, procede-se, ainda, a uma análise descritiva adicional de 
comparação de médias entre dois grupos de universidades categorizadas por tamanho, sendo grupo 1, correspondente às instituições com tamanho inferior, e grupo 2, aglutinando as maiores. Como se pode ver na tabela 4 , não foi detectada diferença significativa entre os dois grupos para nenhum dos índices administrativos nem para o IDD. Destaca-se, entretanto, que um maior número de universidades permite avançar nesta tentativa de encontrar distinções e que esta foi uma primeira tentativa, mostrando que há uma certa homogeneidade de indicadores de desempenho.

Tabela 4 - Comparação de médias de variáveis entre IFES grandes e pequenas

\begin{tabular}{lrrr}
\hline Var. & $\begin{array}{c}\text { Média Grupo 1 } \\
\text { (menores) }\end{array}$ & $\begin{array}{r}\text { Média Grupo 2 } \\
\text { (maiores) }\end{array}$ & valor-p \\
\hline IDD & 2,88 & 3,08 & 0,257 \\
I1 & 7241,77 & 7750,62 & 0,650 \\
I2 & 13,07 & 13,03 & 0,976 \\
I3 & 9,32 & 9,70 & 0,796 \\
I4 & 1,81 & 1,41 & 0,226 \\
I5 & 0,84 & 0,85 & 0,711 \\
I6 & 0,085 & 0,125 & 0,174 \\
I7 & 3,66 & 3,94 & 0,181 \\
I8 & 3,53 & 3,62 & 0,649 \\
I9 & 0,61 & 0,67 & 0,512 \\
\hline \multicolumn{4}{c}{ Fonte: Elaboração própria }
\end{tabular}

\subsection{Análise de relações entre desempenho e indicadores administrativos}

Como comentado, a segunda etapa da pesquisa concretiza o principal objetivo da mesma que é verificar a existência de alguma causalidade entre os indicadores administrativos das IFES e o desempenho dos seus alunos. Para tanto, procede-se a uma análise de possíveis relações entre o IDD e os índices administrativos, conforme as hipóteses propostas na seção 2.3. Antes da análise através de regressão em corte transversal do IDD sobre os índices administrativos, realizou-se uma análise de correlação entre todos os índices, o IDD e o tamanho da IFES, buscando detectar algum indício de confirmação de hipóteses. O modelo de regressão utilizado na fase seguinte tem o IDDi (IDD da IFES i) como variável dependente e os indicadores administrativos da IFES (Indicador ${ }_{i}$ ) como independentes, além do tamanho da instituição que é utilizado como variável de controle, como a seguir especificado. 


$$
I D D_{i}=\alpha+\beta_{i} \text { Indicador }_{i}+\text { TAM }_{i}+\varepsilon_{i} .
$$

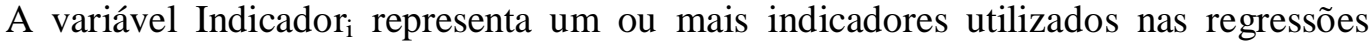
realizadas. O tamanho da IFES $\left(\mathrm{TAM}_{\mathrm{i}}\right)$ é utilizado como variável de controle. $\mathrm{O}$ fator de erro aleatório $\left(\varepsilon_{\mathrm{i}}\right)$ controla tanto o erro de medição das variáveis como a omissão de variáveis explicativas relevantes que não tenham sido utilizadas.

\section{RESULTADOS}

Os resultados da análise exploratória de causalidade entre os indicadores administrativos e o desempenho dos alunos medido pelo IDD mostraram algum sucesso na análise de correlação inicial como se pode ver na tabela 5. Detectou-se uma correlação significativa entre o IDD e alguns indicadores administrativos. Tal correlação significativa é negativa com o índice 3 e positiva com os índices 5 e 9. A princípio, estes resultados confirmam as hipóteses relativas aos índices 3, 5 e 9. Ao mesmo tempo, também nota-se a ausência de relação com o índice 1 referente ao custo do aluno que se esperava uma relação positiva. Procede-se à execução da regressão do IDD sobre os índices administrativos para confirmar estes resultados e a capacidade explicativa dos indicadores, que foram considerados isoladamente, em conjunto e controlado pelo tamanho da IFES. 
Tabela 5 - Coeficientes de correlação entre IDD e indicadores de gestão

\begin{tabular}{rrr} 
& \multicolumn{1}{c}{ TAM } & \multicolumn{1}{c}{ IDD } \\
\cline { 2 - 3 } IDD & 0,187 & \\
& $(0,351)$ & \\
I1 & 0,058 & 0,209 \\
& $(0,780)$ & $(0,306)$ \\
I2 & $-0,089$ & $-0,171$ \\
& $(0,660)$ & $(0,395)$ \\
I3 & 0,093 & $-0,438$ \\
& $(0,651)$ & $(0,025)$ \\
I4 & $-0,313$ & $-0,035$ \\
& $(0,128)$ & $(0,870)$ \\
I5 & 0,069 & 0,452 \\
& $(0,733)$ & $(0,018)$ \\
I6 & 0,347 & $-0,058$ \\
& $(0,082)$ & $(0,784)$ \\
I7 & 0,391 & $-0,052$ \\
& $(0,048)$ & $(0,801)$ \\
I8 & 0,109 & 0,214 \\
& $(0,589)$ & $(0,285)$ \\
I9 & $-0,035$ & 0,325 \\
& $(0,862)$ & $(0,098)$ \\
\hline
\end{tabular}

Em seguida, desenvolveu-se o modelo proposto (equação 1) fazendo alguns ajustes específicos para contrastar o conjunto de hipóteses proposto na seção 2.3. A primeira abordagem consistiu na regressão do IDD sobre cada um dos indicadores administrativos individualmente e, também, controlado pelo fator tamanho para cada estimação. A tabela 6 resume os resultados obtidos que confirmam os resultados iniciais detectados na análise de correlação. 
Tabela 6 - Estimativas dos modelos de IDD sobre cada indicador administrativo

\begin{tabular}{|c|c|c|c|c|c|}
\hline Modelo 1 & $\begin{array}{c}\text { Intercepto } \\
2,056^{* * *} \\
(2,580)\end{array}$ & $\begin{array}{r}\text { índice } 1 \\
0,000 \\
(0,990)\end{array}$ & $\begin{array}{r}\text { TAM } \\
0,074 \\
(0,890) \\
\end{array}$ & $\begin{array}{r}\text { R2 ajust } \\
-0,005\end{array}$ & $\begin{array}{r}\text { valor-p }(F) \\
0,404\end{array}$ \\
\hline Modelo 2 & $\begin{array}{c}\text { Intercepto } \\
2,560^{\text {*** }} \\
(3,010)\end{array}$ & $\begin{array}{r}\text { índice } 2 \\
-0,019 \\
(-0,780)\end{array}$ & $\begin{array}{r}\text { TAM } \\
0,072 \\
(0,870)\end{array}$ & $\begin{array}{r}\text { R2 ajust } \\
-0,020\end{array}$ & $\begin{array}{r}\text { valor-p }(\mathrm{F}) \\
0,483\end{array}$ \\
\hline Modelo 3 & $\begin{array}{l}\text { Intercepto } \\
2,621^{* * *} \\
(3,680)\end{array}$ & $\begin{array}{c}\text { índice } 3 \\
-0,056^{* *} \\
(-2,530) \\
\end{array}$ & $\begin{array}{r}\text { TAM } \\
0,097 \\
(1,290) \\
\end{array}$ & $\begin{array}{r}\mathrm{R} 2 \text { ajust } \\
0,181\end{array}$ & $\begin{array}{l}\text { valor-p }(\mathrm{F}) \\
0,039^{* *}\end{array}$ \\
\hline Modelo 4 & $\begin{array}{c}\text { Intercepto } \\
2,195^{* *} \\
(2,340)\end{array}$ & $\begin{array}{r}\text { índice } 4 \\
0,015 \\
(0,120) \\
\end{array}$ & $\begin{array}{r}\text { TAM } \\
0,083 \\
(0,890) \\
\end{array}$ & $\begin{array}{r}\text { R2 ajust } \\
-0,052\end{array}$ & $\begin{array}{r}\text { valor-p }(F) \\
0,668\end{array}$ \\
\hline Modelo 5 & $\begin{array}{r}\text { Intercepto } \\
1,100 \\
(1,310)\end{array}$ & $\begin{array}{l}\text { índice } 5 \\
1,514^{* *} \\
(2,460)\end{array}$ & $\begin{array}{r}\text { TAM } \\
0,065 \\
(0,870) \\
\end{array}$ & $\begin{array}{r}\mathrm{R} 2 \text { ajust } \\
0,165\end{array}$ & $\begin{array}{c}\text { valor-p }(\mathrm{F}) \\
0,044^{* *}\end{array}$ \\
\hline Modelo 6 & $\begin{array}{c}\text { Intercepto } \\
2,416^{\text {**** }} \\
(2,890)\end{array}$ & $\begin{array}{r}\text { índice } 6 \\
-0,553 \\
(-0,430)\end{array}$ & $\begin{array}{r}\text { TAM } \\
0,068 \\
(0,740)\end{array}$ & $\begin{array}{c}\text { R2 ajust } \\
-0,061\end{array}$ & $\begin{array}{r}\text { valor-p }(\mathrm{F}) \\
0,753\end{array}$ \\
\hline Modelo 7 & $\begin{array}{c}\text { Intercepto } \\
2,676^{* * *} \\
(3,010) \\
\end{array}$ & $\begin{array}{r}\text { índice } 7 \\
-0,099 \\
(-0,540) \\
\end{array}$ & $\begin{array}{r}\text { TAM } \\
0,075 \\
(0,790) \\
\end{array}$ & $\begin{array}{r}\text { R2 ajust } \\
-0,055\end{array}$ & $\begin{array}{r}\text { valor-p }(\mathrm{F}) \\
0,712\end{array}$ \\
\hline Modelo 8 & $\begin{array}{r}\text { Intercepto } \\
1,759^{*} \\
(1,930) \\
\end{array}$ & $\begin{array}{r}\text { índice } 8 \\
0,164 \\
(0,990)\end{array}$ & $\begin{array}{r}\text { TAM } \\
0,068 \\
(0,840) \\
\end{array}$ & $\begin{array}{r}\text { R2 ajust } \\
-0,005\end{array}$ & $\begin{array}{r}\text { valor-p }(F) \\
0,404\end{array}$ \\
\hline Modelo 9 & $\begin{array}{c}\text { Intercepto } \\
1,769^{* *} \\
(2,270)\end{array}$ & $\begin{array}{c}\text { índice } 9 \\
0,705^{*} \\
(1,760)\end{array}$ & $\begin{array}{r}\text { TAM } \\
0,082 \\
(1,050)\end{array}$ & $\begin{array}{r}\mathrm{R} 2 \text { ajust } \\
0,074\end{array}$ & $\begin{array}{r}\text { valor-p }(\mathrm{F}) \\
0,153\end{array}$ \\
\hline
\end{tabular}

***, ** e * indicam significação ao nível de 1,5 e $10 \%$ respectivamente, valores do estatístico $\mathbf{t}$ entre parenteses. Fonte: Elaboração própria

Com relação ao índice 3, rejeita-se a hipótese nula de ausência de relação significativa aceitando-se, portanto, a hipótese alternativa de existência de tal relação, o que significa a existência de uma relação de causalidade do índice 3 em relação ao IDD. Desta forma, a relação número de alunos por número de funcionários atual do conjunto de IFES apresenta efeito positivo sobre o desempenho do aluno. Entretanto, o equivalente índice relativo ao número de professores não apresentou efeito sobre o IDD conforme esperado teoricamente. 
O índice 5 também apresentou efeito no desempenho na direção da proposta teórica de um efeito positivo. Isto significa que, efetivamente, a maior presença de alunos em tempo integral é positiva para o desempenho do corpo discente.

O resultado do modelo 6 indica que não se pode rejeitar a hipótese nula de ausência de relação significativa entre o IDD e o índice 6 (número de alunos na pós-graduação por número total de alunos) não se confirmando o previsto efeito positivo do envolvimento discente na pós-graduação.

O modelo 9 apresentou resultado significativo com relação ao efeito do índice 9 que permitiu-se rejeitar a hipótese nula de ausência de relação, nos levando a aceitar a hipótese alternativa de existência de relação positiva do índice 9 relativamente ao IDD. Assim, a taxa de sucesso na graduação tem um efeito positivo no IDD conforme previsto teoricamente.

Um outro resultado que merece atenção é o do modelo 1, cujo resultado não permitiu rejeitar a hipótese estatística de ausência de relação. Isto leva ao resultado de que, na verdade, o custo por aluno de uma IFES não tem efeito sobre o desempenho discente. Crê-se que seria importante que o maior custo se traduzisse em melhor infra-estrutura, bem como em mais numeroso e qualificado quadro de professores e funcionários, o que deve resultar em melhor desempenho dos alunos egressos. Resultado que também merece menção em um raciocínio similar é a ausência de relação da capacitação docente (índice 8) com o desempenho discente.

\section{CONCLUSÕES E PERSECTIVAS}

Segundo Vieira e Vieira (2004), as instituições públicas de ensino superior brasileiras têm sido alvo de diversos questionamentos há três décadas, principalmente devido a problemas de gestão. Neste contexto se inserem as IFES que são o objeto de pesquisa deste trabalho, que consideramos pertinente, dada a necessidade de verificar-se com maior exatidão aspectos de gestão e de desempenho delas. Em um "mercado educacional" como o que atualmente se vive no Brasil, parece natural que cresçam as críticas a instituições públicas de ensino. Estas têm um comportamento distinto daqueles entes privados que atuam no setor de ensino superior, que são maioria nos dias de hoje. Estes talvez sejam os maiores beneficiários das críticas que se dirigem à instituição pública de ensino. Gonçalves, Colauto e Beuren 
(2007) comentam sobre o crescimento da participação privada no setor de ensino superior que chega hoje, segundo os autores, a oferecer $80 \%$ das vagas. Nos parece oportuno fazer uma análise mais detalhada das instituições públicas federais que atuam neste entorno.

A partir de um objetivo principal de analisar se alguns aspectos do desempenho administrativo destas instituições tem efeito sobre o desempenho discente, realizou-se uma pesquisa que permitiu aprofundar o conhecimento sobre as mesmas, que têm sido alvo de crescentes avaliações por parte do governo. Dispondo de um conjunto de indicadores de gestão e de dados indicativos do desempenho de egressos das IFES, buscou-se encontrar relações de causalidade entre tais indicadores e o desempenho dos alunos para uma amostra de 27 IFES, 50\% do universo de IFES, no ano 2005.

Os resultados permitem inferir que há uma certa pró-atividade discente relativamente à sua formação. Isto porque o grau de participação estudantil e a taxa de sucesso na graduação (indicadores 5 e 9, respectivamente) mostraram ter um efeito positivo no desempenho deste coletivo no Enade. Considera-se que este é um aspecto positivo e importante a destacar num entorno tão cheio de dificuldades.

Também confirmando as expectativas, o indicador 3 apresentou um efeito favorável no desempenho. Assim, a relação entre número de alunos e de funcionários está em nível favorável à formação em nível de graduação. Por outro lado, não se encontrou um esperado efeito equivalente da relação com o número de professores.

Merece também destaque a ausência de um esperado efeito positivo do custo por aluno no desempenho do aluno egresso, uma vez que é desejável que o custo destas instituições deve se traduzir num conjunto de elementos estruturais favoráveis à formação discente. A infra-estrutura física e de pessoal deve traduzir-se em melhor formação. Ao mesmo tempo, também sabe-se das dificuldades orçamentárias que passam estas instituições, apesar de ter ocorrido alguma melhora nos últimos anos. No entanto, o beneficio do investimento em IFES não gera retorno imediato como se pode esperar no investimento empresarial. O investimento em educação exige um maior prazo para ser verificado. Especificamente no entorno desta pequisa, por exemplo, os discentes beneficiários de novos laboratórios e outros recursos disponibilizados a eles hoje, durante sua formação, terão seu desempenho como egresso avaliado ao formar-se, o que ocorrerá em um, dois ou mais anos. Em uma visão mais 
pessimista, que não se quer aqui compartir, poderia estar ocorrendo alguma falha na aplicação dos poucos recursos disponíveis e isto ocasionaria o não direcionamento dos mesmos para pontos onde mais contribuiria para a formação discente em nível de graduação.

A ausência do efeito positivo do custo, associada aos índices relacionados com a atividade discente permite concluir que os alunos parecem estar sendo capazes de superar eventuais dificuldades de infra-estrutura que enfrentam.

Por fim, destaca-se que a pesquisa merece ser aprofundada. Considera-se que mais dados característicos das IFES, bem como ampliar o número de instituições e mais períodos de análise permitirão obter resultados mais robustos. Além destes aspectos, pode-se mencionar também, por exemplo, que seria muito bom dispor de mais índices de desempenho das IFES e não somente o resultado do Enade. Alguns indicadores como a colocação dos egressos no mercado de trabalho, ou o ingresso dos mesmos em programas de pós-graduação stricto sensu, ou ainda sua produção intelectual, poderiam ser outros índices de desempenho de graduados úteis a esta pesquisa. Esta é a perspectiva de continuidade na qual se pretende melhorar o conhecimento sobre este conjunto de instituições e seu papel na formação em nível de graduação, bem como entender melhor o conjunto de indicadores trabalhados pelo governo. Nesta mesma direção também se trabalhará a implementação de outros modelos empíricos, permitindo mais solidez aos resultados. 


\section{REFERÊNCIAS}

BRASIL. Tribunal de Contas da União - TCU. Decisão 408 - Plenário. Relatório Consolidado de Auditoria Operacional. Brasília, DF, 24 de abril de 2002. Disponível em: <https://contas.tcu.gov.br/portaltextual/PesquisaFormulario>. Acesso em: 20 jun. 2006.

Tribunal de Contas da União - TCU; Secretaria de Educação Superior - SESu/MEC; Secretaria Federal de Controle Interno - SFC. Orientações para o cálculo dos indicadores de gestão: decisão TCU no 408/2002 - plenário. Versão revisada em janeiro de 2006.

Lei $\mathbf{n}^{\circ}$ 9.131, de 24 de novembro de 1995. Altera dispositivos da Lei no 4.024, de 20 de dezembro de 1961 e dá outras providências. Diário Oficial da República Federativa do Brasil, Brasília, DF, 24 nov. 1995. Edição Extra, p. 19257. Disponível em: <http://www.planalto.gov.br/ccivil_03/Leis/L9131.htm>. Acesso em: 24 set. 2006.

Lei no 10.861, de 14 de abril de 2004. Institui o Sistema Nacional de Avaliação da Educação Superior - SINAES e dá outras providências. Leis, Brasília, DF, 2004. Disponível em: <http://portal.mec.gov.br/arquivos/pdf/10861.pdf>. Acesso em: 24 set. 2006.

DIAS SOBRINHO, José. Universidade e avaliação: entre a ética e o mercado. Florianópolis: Insular, 2002

DIAS SOBRINHO, José e RISTOFF, Dilvo I. (Organizadores). Avaliação e compromisso público: a educação superior em debate. Florianópolis: Insular, 2003.

DURHAM, Eunice R. E SCHWARTZMAN, Simon (organizadores). Avaliação do ensino superior. São Paulo: Editora da Universidade de São Paulo, 1992.

GONÇALVES, Caio Márcio; COLAUTO, Romualdo Douglas e BEUREN, Ilse Maria. Proposta de indicadores para sistema de inteligência competitiva em instituição de ensino superior. Revista Produção Online, Vol. 7, Num. 1, abril/2007.

GUTERRES, Clóvis. et al. Sistema de avaliação da educação superior (SINAES) - as políticas educacionais do Governo Lula: o sistema de avaliação. In ANDES-SN. A Contrareforma da educação superior. Brasília: ANDES-SN, 2004.

HALL, Bronwyn H. Investment and research and development at the firm level: Does the source of financing matter? NBER Working Paper Series 4096, June 1992.

RISTOFF, Dilvo I. Algumas definições de avaliação. in DIAS SOBRINHO, José e RISTOFF, Dilvo I. (Organizadores). Avaliação e compromisso público: a educação superior em debate. Florianópolis: Insular, 2003.

RISTOFF, Dilvo I. Apresentação In DIAS SOBRINHO, José. Universidade e avaliação: entre a ética e o mercado. Florianópolis: Insular, 2002 
ROCHA, Carlos Henrique e MACHADO, André Luiz. O Desempenho universitário acadêmico-pedagógico versus o desempenho financeiro. Revista de Economia Contemporânea. Rio de Janeiro, 7 (1): 161-168, janeiro a junho de 2003.

ROTHEN, José Carlos. O vestibular do provão. in DIAS SOBRINHO, José e RISTOFF, Dilvo I. (Organizadores). Avaliação e compromisso público: a educação superior em debate. Florianópolis: Insular, 2003.

SILVA, César Augusto Tibúrcio. MORGAN, Beatriz Fátima e COSTA, Patrícia de Souza. Desenvolvimento e aplicação de uma metodologia de cálculo do custo aluno de instituições públicas de ensino superior: Um Estudo de Caso. RAP. Rio de Janeiro, 38(2): 243-60, Mar./Abr. 2004

STEVENS, J. Applied multivariate statistics for the social sciences, $3^{\mathrm{a}}$ ed. Mahwah, NJ:L. Erlbaum Associates, 1996.

TABACHNICK, B.G. e FIDELL, L. S. Using multivariate statistics, NY: Harper Collins, 1989.

TACQ, J. Multivariate analysis techniques in social science research, Londres: Sage, 1997.

TATSUOKA, M. M. Multivariate analysis, NY: Wiley, 1988.

VAN DE GEER, J. P. Introduction to multivariate analysis for the social sciences, San Francisco: WH Freeman ,1971.

VIEIRA, Euripedes Falcão e VIEIRA, Marcelo Milano Falcão. Funcionalidade burocrática nas universidades federais: Conflito em Tempos de Mudança. Revista de Administração Contemporânea, v. 8, n. 2, Abr./Jun. 2004.

WOLYNEC, E. O uso de indicadores de desempenho para a avaliação institucional. In DURHAM, Eunice R. E SCHWARTZMAN, Simon (organizadores). Avaliação do ensino superior. São Paulo: Editora da Universidade de São Paulo, 1992. 